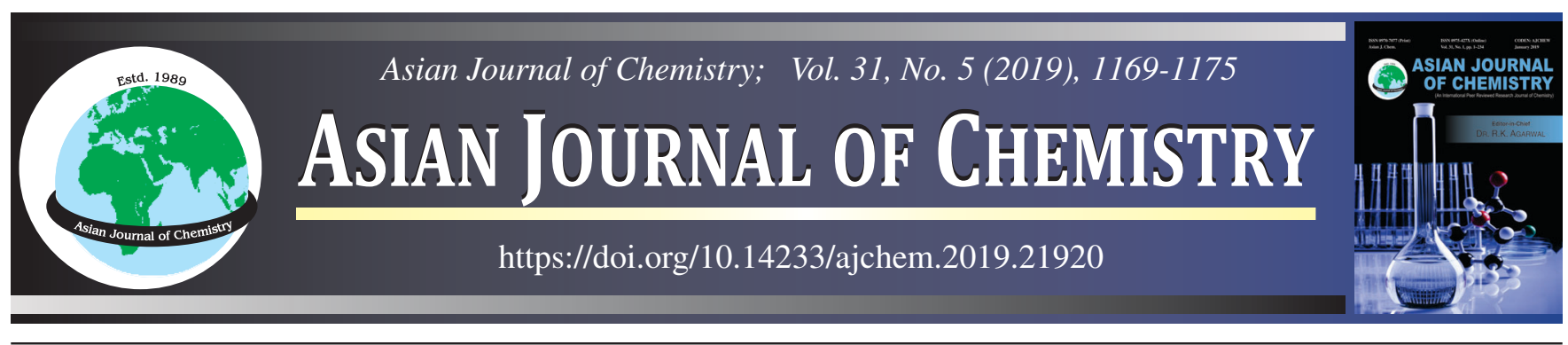

\title{
Interaction of Lorazepam with Planar Bilayer Lipid Membrane and Development of Impedimetric Sensor
}

\section{S. SivAKUmar ${ }^{1,2}$, S. RAMEShKUmar ${ }^{3}$, S. SATHISHKUMAR $^{2}$ and A. SAnKAR ${ }^{1, *}$}

${ }^{1}$ Department of Chemistry, Kandaswami Kandar's College, P. Velur, Namakkal-638182, India

${ }^{2}$ Advanced Biomaterial Laboratory, Department of Chemistry, Sri Vijay Vidyalaya College of Arts and Science, Dharmapuri-636807, India ${ }^{3}$ Department of Chemistry, Sri Vasavi College, Erode-638316, India

*Corresponding author: E-mail: sivasankarchem2018@gmail.com

Received: 5 January 2019;

Accepted: 5 February 2019;

Published online: 28 March 2019;

AJC-19350

Artificial planar bilayer phospholipid membrane was formed in $\mathrm{KCl}$ bath solutions and its electrical properties have been analyzed using
electrochemical impedance spectroscopy. The stability of planar bilayer lipid membrane depends on concentration of $\mathrm{KCl}$ in the bath.
Changes in the electrical properties of planar bilayer lipid membrane with the addition of lorazepam were also studied using electrochemical
impedance spectroscopy. Lorazepam gets partitioned into bilayer lipid membrane and exhibited a fluidization effect. The ionic conductance
across the bilayer lipid membrane increased with the addition of lorazepam to the bath. An impedimetric sensor was developed for
quantification of lorazepam in solution. I

Keywords: Planar bilayer lipid membrane, Lorazepam, EIS, Drug-membrane interaction, Capacitance.

\section{INTRODUCTION}

Bilayer phospholipid membrane systems mimic cell membranes and could be used for studying interaction between drug molecules and cell membranes by forming lipid bilayer architecture of the cell membranes such as lipid vesicles, bilayer lipid membranes, supported bilayer lipid membranes etc. [1-4]. The bilayer phospholipid membranes are extensively used for studying drug-membrane interaction $[5,6]$. Benzodiazepines are a class of drugs used as pre-medicant to reduce anxiety that produce sedation and amnesia in conscious patients. Compared to other anesthetic agents, benzodiazepines are extraordinarily safe in many ways. They have high therapeutic indices (ratio of lethal to therapeutic dosage).

Benzodiazepine drugs are weak organic bases with the most basic nitrogen being the $\mathrm{N}_{4}$ and form salts with strong acids. Unfortunately, such strong acid salts are unstable and readily undergo sequential hydrolyses, first at the imine bond and then at the amide to yield inactive products. The first hydrolysis reaction is reversible; however, amide hydrolysis eliminates GABA receptor activity $[7,8]$. Lorazepam is a short-acting benzodiazepine, which is used in severe anxiety disorders and insomnia, in convulsions, as a premedicant and sedative for surgical and other procedures. Dependency may develop after regular use of the drug. Withdrawal symptoms may be particularly severe. Drowsiness, sedation and ataxia are the most frequent adverse effects [9]. Lorazepam may be administered by oral, intravenous or intramuscular route. Benzodiazepine is highly effective drug but, it has a slow onset and relatively long duration of action that are often inconvenient in anesthesia practice. Often, it is rated as a short-acting drug; because it has no pharmacologically active metabolites. The duration of action of lorazepam appears to be determined by receptor binding kinetics rather than plasma pharmacokinetics.

Only a few studies have been conducted on the nonspecific interaction of benzodiazepines with model membranes [1012] and little work has been done on lorazepam-bilayer lipid membrane interaction. Benzodiazepines bind to specific receptors, but also interact nonspecifically with the lipid part of the membrane. Benzodiazepines bind to specific receptors, but also interact nonspecifically with the lipid part of the membrane. Lorazepam was found to localize at the polar region of the bilayer $[10,13]$. The extent of interaction and localization of benzodiazepines at the lipid-water interface depends on the

This is an open access journal, and articles are distributed under the terms of the Creative Commons Attribution-NonCommercial-ShareAlike 4.0 (CC BY-NC-SA 4.0) International License which allows readers to freely read, download, copy, distribute, print, search, or link to the full texts of its articles and to use them for any other lawful non-commercial purpose as long as the original source is duly acknowledged. 
nature of the medium, the membrane composition and the chemical structure of the drug $[11,13]$. On the other hand, benzodiazepines were shown to localize at the hydrocarbon core of the membrane $[12,13]$. The two results give two different views on the interaction of benzodiazepines with model membranes and the implication of these results will be discussed. It is well known that the black lipid membranes used as a model membrane in our studies can be very well characterized using electrochemical impedance spectroscopy (EIS) [14-21]. Moreover, the impedance technique has provided a non-invasive means of characterizing the electrical properties of many systems $[14,21]$. This paper describes the real time characterization of lorazepam-bilayer membrane interactions using electrochemical impedance spectroscopy and development of an impedimetric sensor for its detection.

\section{EXPERIMENTAL}

Potassium chloride $(\mathrm{KCl})$ used is of analytical grade and is purchased from Merck, Germany. $99 \%$ of L- $\alpha$-Phosphatidylcholine was purchased from Sigma Aldrich. Stock solution of L- $\alpha$-phosphatidylcholine $(50 \mathrm{mg} / \mathrm{mL})$ was prepared by using Analytical Grade chloroform. Bilayer lipid membrane (BLM) forming dispersions were prepared in $n$-decane (Merck, Germany). All the aqueous solutions used in our studies were prepared using Milli-Q water $\left(\mathrm{R}>18 \mathrm{M} \Omega \mathrm{cm}^{-1}\right.$ ). Lorazepam was extracted from commercially available calmese tablets, using $90 \%$ ethanol solution, in its hydrochloride form. It is precipitated by adding excess water to the $90 \%$ ethanol solution. The precipitate was separated by filtration, dried and used for studies.

Bilayer lipid membrane chamber: Interaction of lorazepam with planar lipid membranes was studied using indigenously constructed BLM chambers. Two $24 \mathrm{~mm}$ diameter cavities, each of $5 \mathrm{~mL}$ capacity were drilled in a polished PMMA block of dimension $85 \mathrm{~mm} \times 60 \mathrm{~mm} \times 22 \mathrm{~mm}$. The cavities are exactly aligned and almost touch each other. The cavities were drilled in a computerized numerical control lathe. At the meeting point of the cavities the block was cut into two halves. A hole of diameter $1.34 \mathrm{~mm}$ was drilled in a $1 \mathrm{~mm}$ thick PMMA sheet and chamfered using a $1.25 \mathrm{~mm}$ drill bit from both sides to equal depths to form the membrane-supporting aperture. The aperture was examined through a travelling microscope with a magnification of $10 \mathrm{x}$ and its diameter was measured. The septum having perfect circular aperture with minimum boundary ripples was used for the studies. This septum was inserted between the two halves of the chamber blocks such that the aperture is at one-third distance from the bottom of the cavity and glued with utmost care.

Fabrication of electrodes and faraday cage: A two-electrode setup was used for studying the interaction of lorazepam with planar or black lipid membrane. The silver-silver chloride electrodes were fabricated by following standard procedures. Silver wire of $1 \mathrm{~mm}$ diameter was anodized in $0.1 \mathrm{M} \mathrm{KCl}$ solution to form the $\mathrm{AgCl}$ coating over the wire [22,23]. In AC measurements the two electrodes used are $\mathrm{Ag} / \mathrm{AgCl}$ electrodes. The electrical connectivity between the electrolytic solution in the cavities and electrode immersed solutions was given by $\mathrm{U}$ shaped salt bridges made of glass filled with $1.5 \%$ agar-agar gel and saturated with $\mathrm{KCl}$. The currents involved in the BLM experiments are extremely low, which are of the order 10-12 A. Any stray current pick-up will greatly affect the readings. Hence, the BLM set-up (the chamber electrode, stirring units etc.) was placed in a metal cage called Faraday $[24,25]$ and the cage was grounded. Utmost care was taken to avoid straycurrent leakage between the two aqueous chambers due to cracks in the septum in the case of black lipid membrane studies.

Preparation of BLM forming dispersion and formation of planar BLM: $100 \mu \mathrm{L}$ of chloroform stock solution of the $\mathrm{L}-\alpha$-phosphatidylcholine $(50 \mathrm{mg} / \mathrm{mL})$ was taken in a screwcap bottle and nitrogen gas was purged forcibly into the tube in order to form a dry thin film of phospholipids and to evaporate chloroform. The phospholipids film was then immediately dispersed in $200 \mu \mathrm{L}$ of $n$-decane and used as the BLM forming dispersion. About $1 \mathrm{~mL}$ of the lipid dispersion in $n$-decane was applied on the septum aperture as a preconditioning step [2] and dried. Then required bathing solutions were taken in both compartments of the BLM chamber. Salt bridges were placed on both the sides. After placing the block on a stand electrical connections were made. Approximately $5 \mu \mathrm{L}$ of the BLM forming lipid dispersion was taken in a microlitre syringe. The tip of the syringe was immersed in the bath solution and held touching the aperture. The lipid dispersion was then delivered directly over the aperture. The dispersion spreads and sticks to the aperture as a lens and then slowly thins down. The solvent molecules were slowly excluded and phospholipids molecules self assemble into a bilayer to form planar or black lipid membrane.

\section{RESULTS AND DISCUSSION}

Electrical characterization of interaction of lorazepam with BLM: The Nyquist plots recorded for bare and lorazepam partitioned planar BLMs in the frequency range $10 \mathrm{mHz}$ to 1 $\mathrm{MHz}$ in $1 \mathrm{M}, 0.1 \mathrm{M}$ and $0.01 \mathrm{M} \mathrm{KCl}$ bath solutions are shown in Figs. 1-3, respectively.

In general, a biomimetic membrane is considered to have dielectric slabs with different dielectric properties [26]. The flow of ions across each slab gives rise to an ionic current and the accumulation of ions at the boundaries between the slabs gives rise to capacitive current under combination of a resistor and a capacitor, namely by an RC mesh, for ionic and capacitive currents, respectively AC conditions [13,27]. Therefore, each slab in the membrane is simulated by a parallel. A commonly accepted-R(RC)(RC)- model [28] was used to obtain the electrochemical impedance parameters by fitting the experimental impedance data, where $\mathrm{P}$ and $\mathrm{H}$ stands for polar groups and hydrocarbon tails of the bilayer phospholipid membranes, respectively. The electrochemical impedance parameters obtained using the equivalent circuits are shown in Table-1.

From the equivalent circuit it can be seen that there are two time constants. The first RC couple represents membrane - solution interface and the RC couple represents bilayer lipid membrane phase. Each RC couple should have a semicircle in the Nyquist plot, accordingly the first representing the BLM surface bath solution interface semicircle must be at the highest frequencies. The second semicircle should represent the membrane phase formed by the bilayer arrangement of lipid molecules, 


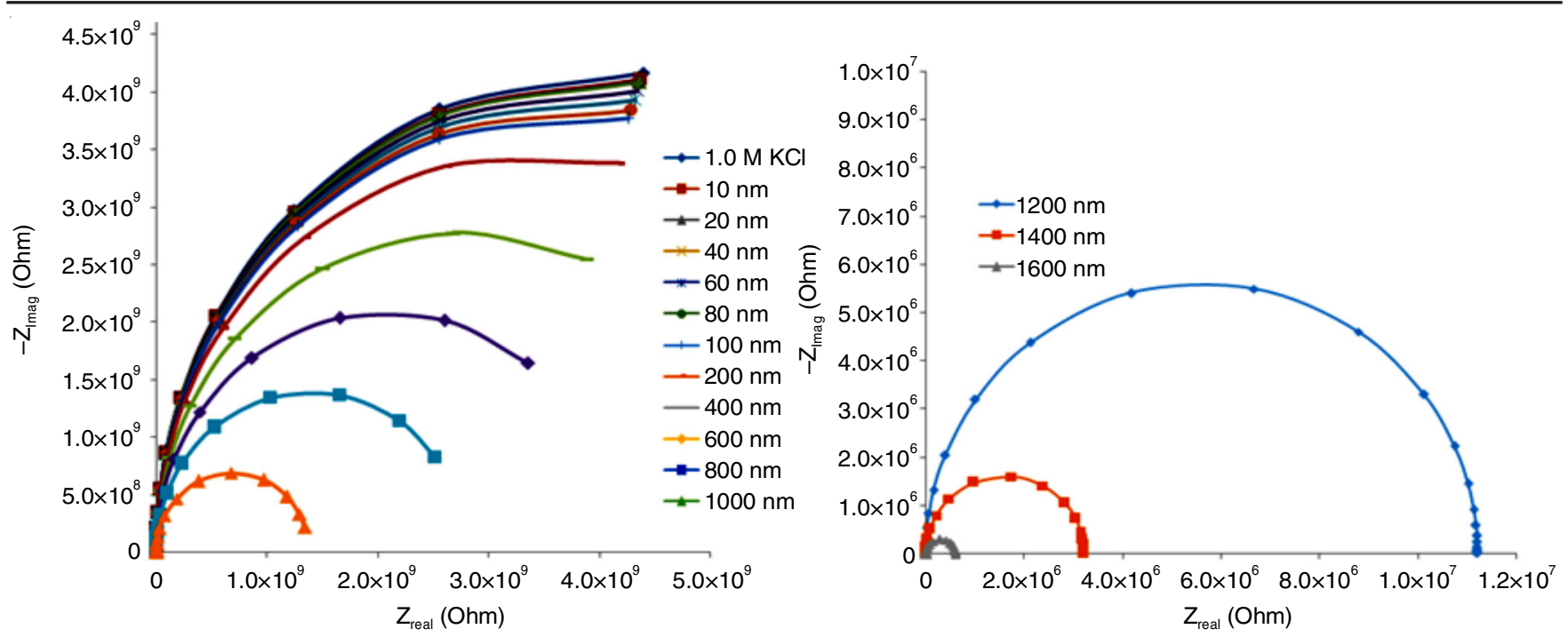

Fig. 1. Impedance spectra recorded for neat and lorazepam doped BLM in $1.0 \mathrm{M} \mathrm{KCl}$ bath
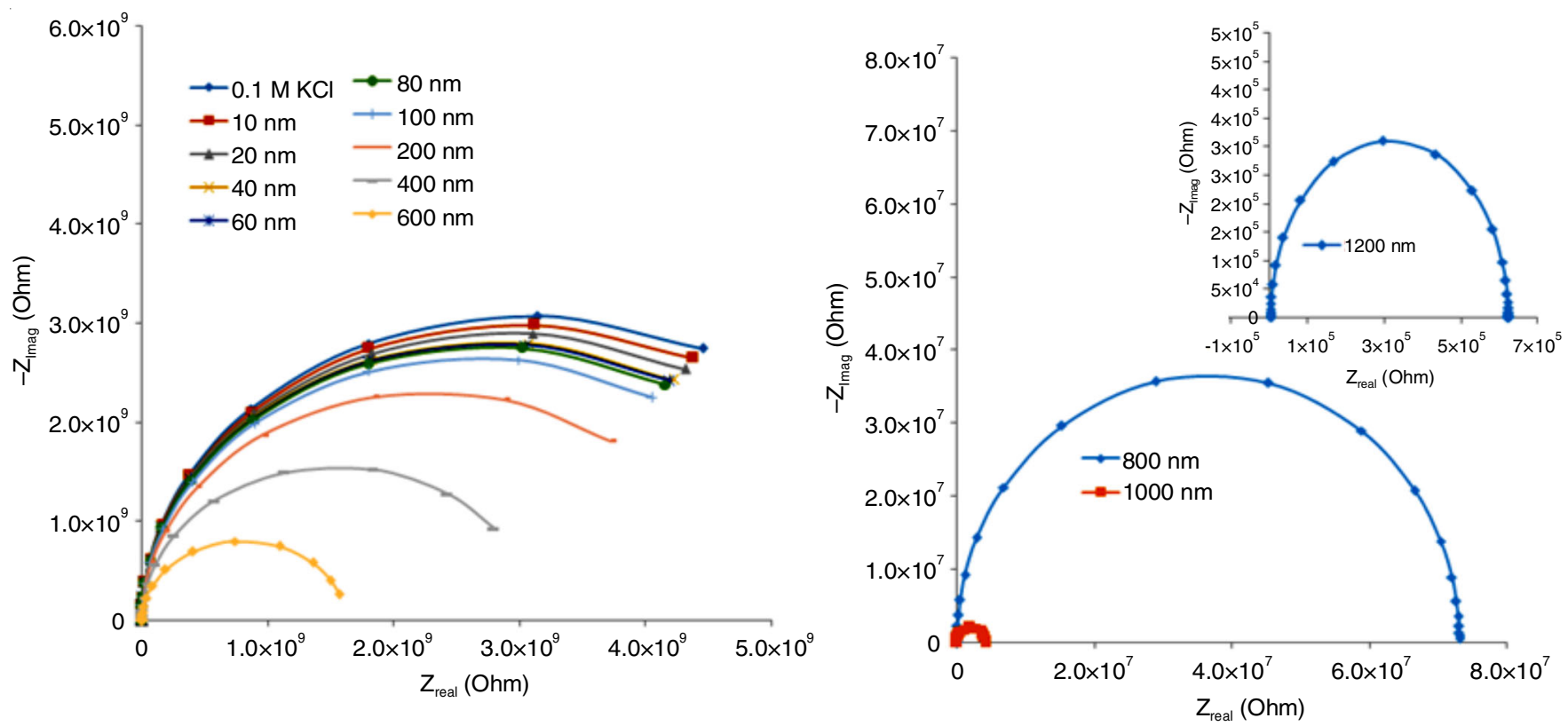

Fig. 2. Impedance spectra recorded for neat and lorazepam doped BLM in $0.1 \mathrm{M} \mathrm{KCl}$ bath

TABLE-1

ELECTROCHEMICAL IMPEDANCE PARAMETERS FOR LORAZEPAM-BLM INTERACTION IN DIFFERENT KCI BATH CONCENTRATION

\begin{tabular}{|c|c|c|c|c|c|c|c|c|c|c|c|c|}
\hline \multirow{2}{*}{$\begin{array}{l}\text { Conc. of } \\
\text { lorazepam } \\
(\mathrm{nM})\end{array}$} & \multicolumn{4}{|c|}{$1.0 \mathrm{M} \mathrm{KCl}$} & \multicolumn{4}{|c|}{$0.1 \mathrm{M} \mathrm{KCl}$} & \multicolumn{4}{|c|}{$0.01 \mathrm{M} \mathrm{KCl}$} \\
\hline & $\begin{array}{c}\mathrm{C}_{\mathrm{P}} \\
(\mathrm{pF})\end{array}$ & $\begin{array}{c}\mathrm{R}_{\mathrm{P}} \\
(\mathrm{K} \Omega)\end{array}$ & $\begin{array}{c}\mathrm{C}_{\mathrm{M}} \\
(\mathrm{nF})\end{array}$ & $\mathrm{R}_{\mathrm{M}}(\mathrm{G} \Omega)$ & $\begin{array}{c}\mathrm{C}_{\mathrm{P}} \\
(\mathrm{pF})\end{array}$ & $\begin{array}{c}\mathrm{R}_{\mathrm{P}} \\
(\mathrm{K} \Omega)\end{array}$ & $\begin{array}{c}\mathrm{C}_{\mathrm{M}} \\
(\mathrm{nF})\end{array}$ & $\mathrm{R}_{\mathrm{M}}(\mathrm{G} \Omega)$ & $\begin{array}{c}\mathrm{C}_{\mathrm{P}} \\
(\mathrm{pF})\end{array}$ & $\begin{array}{c}\mathrm{R}_{\mathrm{P}} \\
(\mathrm{K} \Omega)\end{array}$ & $\begin{array}{c}\mathrm{C}_{\mathrm{M}} \\
(\mathrm{nF})\end{array}$ & $\begin{array}{c}\mathrm{R}_{\mathrm{M}} \\
(\mathrm{G} \Omega)\end{array}$ \\
\hline 0 & 225 & 1.118 & 1.142 & 8.350 & 203 & 1.338 & 1.009 & 6.150 & 192 & 2.012 & 0.917 & 2.890 \\
\hline 10 & 229 & 1.125 & 1.147 & 8.250 & 212 & 1.345 & 1.016 & 5.980 & 198 & 2.036 & 0.922 & 2.750 \\
\hline 20 & 232 & 1.133 & 1.148 & 8.190 & 216 & 1.351 & 1.019 & 5.810 & 206 & 2.098 & 0.926 & 2.640 \\
\hline 40 & 219 & 1.105 & 1.152 & 8.050 & 221 & 1.359 & 1.028 & 5.620 & 215 & 2.112 & 0.933 & 2.410 \\
\hline 60 & 202 & 1.093 & 1.158 & 7.910 & 227 & 1.366 & 1.036 & 5.590 & 226 & 2.123 & 0.942 & 2.190 \\
\hline 80 & 189 & 1.088 & 1.166 & 7.730 & 194 & 1.207 & 1.042 & 5.520 & 231 & 2.142 & 0.948 & 1.950 \\
\hline 100 & 178 & 1.014 & 1.171 & 7.610 & 185 & 1.161 & 1.052 & 5.300 & 239 & 2.165 & 0.963 & 1.730 \\
\hline 200 & 165 & 0.975 & 1.178 & 6.920 & 178 & 1.066 & 1.063 & 4.610 & 165 & 2.041 & 0.964 & 0.610 \\
\hline 400 & 161 & 0.813 & 1.181 & 5.560 & 169 & 1.002 & 1.074 & 3.100 & 141 & 1.982 & 0.963 & 0.0562 \\
\hline 600 & 158 & 0.749 & 1.181 & 4.160 & 156 & 0.981 & 1.075 & 1.610 & 122 & 1.836 & 0.964 & 0.00825 \\
\hline 800 & 154 & 0.611 & 1.182 & 2.790 & 151 & 0.922 & 1.074 & 0.00732 & - & - & - & - \\
\hline 1000 & 147 & 0.530 & 1.181 & 1.380 & 148 & 0.895 & 1.074 & 0.042 & - & - & - & - \\
\hline 1200 & 139 & 0.458 & 1.181 & 0.00112 & 139 & 0.803 & 1.074 & 0.00000062 & - & - & - & - \\
\hline 1400 & 122 & 0.320 & 1.182 & 0.0321 & - & - & - & - & - & - & - & - \\
\hline 1600 & 118 & 0.317 & 1.180 & 0.000000598 & - & - & - & - & - & - & - & - \\
\hline
\end{tabular}



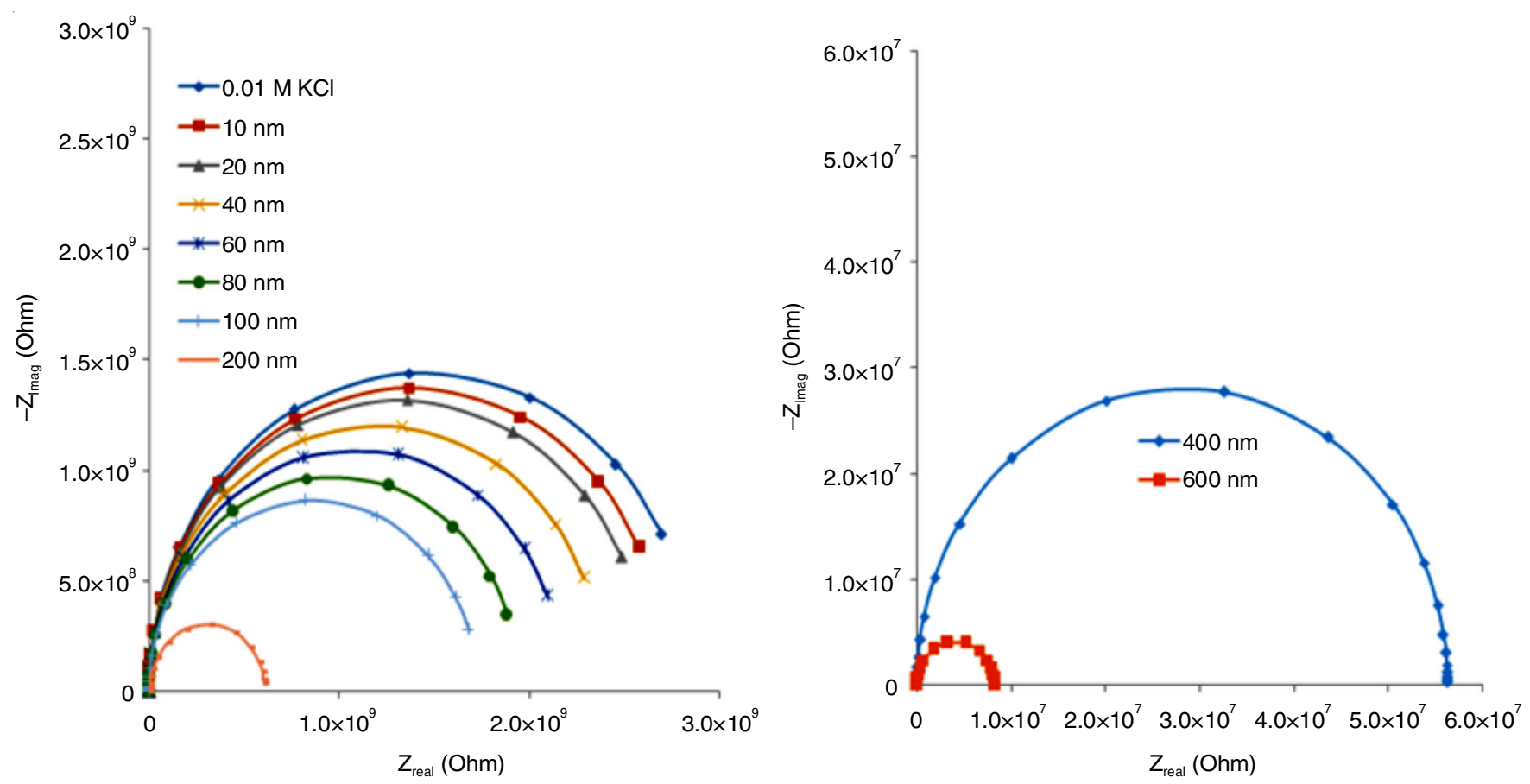

Fig. 3. Impedance spectra recorded for neat and lorazepam doped BLM in $0.01 \mathrm{M} \mathrm{KCl}$ bath

which starts from mid range frequencies and extend up to lower frequencies.

These two semicircles can be explained as follows. Due to excess negative charge on the membrane surface, it attracts oppositely charged ions from the solution and forms a double layer, which is represented by first RC couple. From the impedance plots it is seen that the diameters of the semicircles decrease with lorazepam concentration in the bath solution. This indicates that the decrease in membrane resistance or increase in membrane conductance with lorazepam concentration is a characteristic property of the membrane to become much leakier to smaller cations like $\mathrm{Na}^{+}, \mathrm{K}^{+}$due to fluidization of the membrane in the presence of lorazepam. Since the curves are double semicircle in nature, the lipid bilayers are dielectric layers and have leakage [19].

The membrane capacitance $\left(\mathrm{C}_{\mathrm{m}}\right)$ and its thickness are related by a well known expression $[13,29]$ :

$$
\mathrm{C}_{\mathrm{m}}=\varepsilon_{0} \varepsilon \mathrm{A} / \mathrm{d}
$$

where $\varepsilon_{0}$ is the permittivity of free space $\left(\varepsilon_{o}=8.854 \times 10^{-14} \mathrm{~F}\right.$ $\left.\mathrm{cm}^{-1}\right), \varepsilon$ is the dielectric constant of the lipid bilayer $(\varepsilon=2.05)$ and $\mathrm{A}$ is surface area of BLM [13,29].

The calculated values of thickness of the BLM formed in 1.0 M, 0.1 M and $0.01 \mathrm{M} \mathrm{NaCl}$ bath solutions are 4.5, 5.3 and $5.5 \mathrm{~nm}$, respectively, which are very close to twice the thickness of the lecithin monolayer $(2.5 \mathrm{~nm})[5,13,30]$. Thus, the lipid membrane formed is considered as bilayer membrane.

The bilayer lipid membrane is electrically represented by an equivalent circuit shown in Fig. 4. To find out the electrical component showing more contribution to the net impedance at a particular frequency domain the following rule is applied. If the impedance values of two circuit elements differ greatly, the overall impedance measured at a frequency has more contribution from the circuit element having higher impedance, when they are connected in series. When the circuit elements

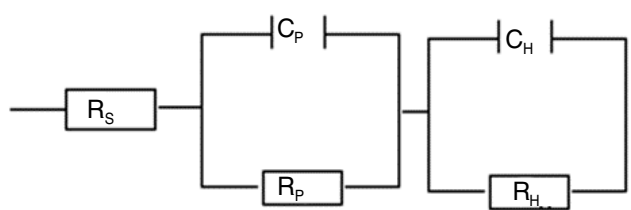

Fig. 4. Equivalent circuit for planar BLM-lorazepam interaction in $\mathrm{KCl}$ bath solutions

are connected in parallel the overall impedance has more contribution from the circuit element of lower impedance $[13,26]$.

Two RC meshes are connected in series in the accepted model for black lipid membrane. The first RC mesh represents aqueous solution- membrane interface [26]. The second one represents the BLM phase [13,26]. These circuit elements have appreciably different impedance values and the overall impedance at any frequency depends on the circuit having higher impedance, in turn the more contribution from that circuit comes from a circuit element having lower impedance by above mentioned rule.

The dispersion of membrane capacitance $\left(\mathrm{C}_{\mathrm{m}}\right)$ and conductance $\left(\mathrm{G}_{\mathrm{m}}\right)$ with frequency are related to the dispersion of conductance $(\mathrm{G})$ and capacitance $(\mathrm{C})$ of polar $(\mathrm{P})$ and hydrocarbon $(\mathrm{H})$ regions of the bilayer phase as follows [31]:

$$
\begin{array}{r}
C_{m}=\frac{C_{H}\left(\frac{G_{P}}{2}\right)^{2}+\left(\frac{C_{P}}{2}\right) G_{H}^{2}+\omega^{2} C_{H}\left(\frac{C_{P}}{2}\right)\left(\frac{C_{P}}{2}+C_{H}\right)}{\left(\frac{G_{P}}{2}+G_{H}\right)^{2}+\omega^{2}\left(\frac{C_{P}}{2}+C_{H}\right)^{2}} \\
G_{m}=\frac{G_{H}\left(\frac{G_{P}}{2}\right)\left(\frac{C_{P}}{2}+G_{H}\right)+\omega^{2}\left[C_{H^{2}}\left(\frac{G_{P}}{2}\right)+\left(\left(\frac{C_{P}}{2}\right)^{2} G_{H}\right)\right]}{\left(\frac{G_{P}}{2}+G_{H}\right)^{2}+\omega^{2}\left(\frac{C_{P}}{2}+C_{H}\right)^{2}}
\end{array}
$$


In each RC mesh the impedance of the capacitive element moves towards the resistance of the resistor with decreasing frequency and becomes close to that of resistor at lower frequencies but still less than resistance of the resistor in the RC mesh.

The bode plots for the variation of total impedance of the membrane and the phase angle of $\mid \mathrm{ZI}$ against the frequency of the applied AC signal in $1 \mathrm{M}, 0.1 \mathrm{M}$ and $0.01 \mathrm{M} \mathrm{KCl}$ bath solutions are shown in Figs. 5-7, respectively.

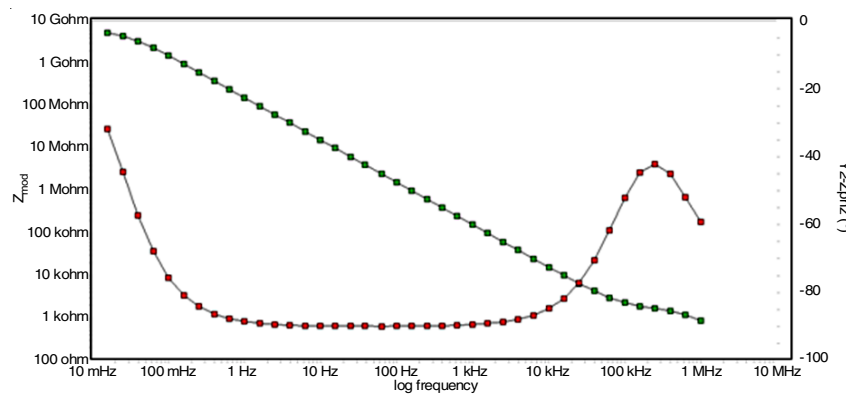

Fig. 5. Bode phase angle and IZI diagrams for planar BLM formed in $1.0 \mathrm{M}$ $\mathrm{KCl}$ bath

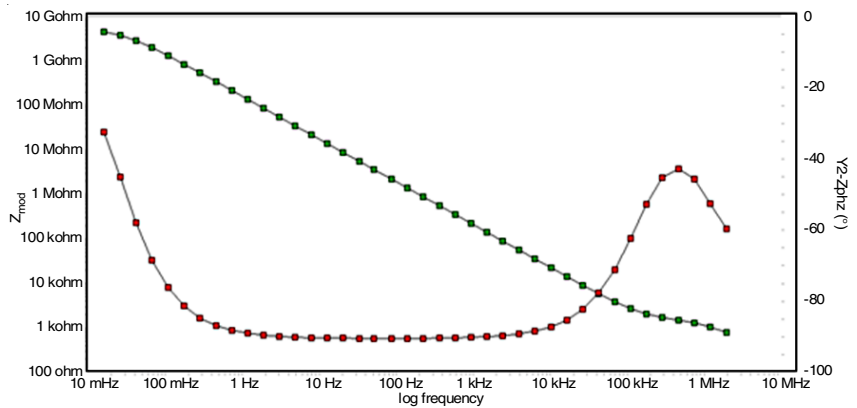

Fig. 6. Bode phase angle and IZI diagrams for planar BLM formed in $0.1 \mathrm{M}$ $\mathrm{KCl}$ bath

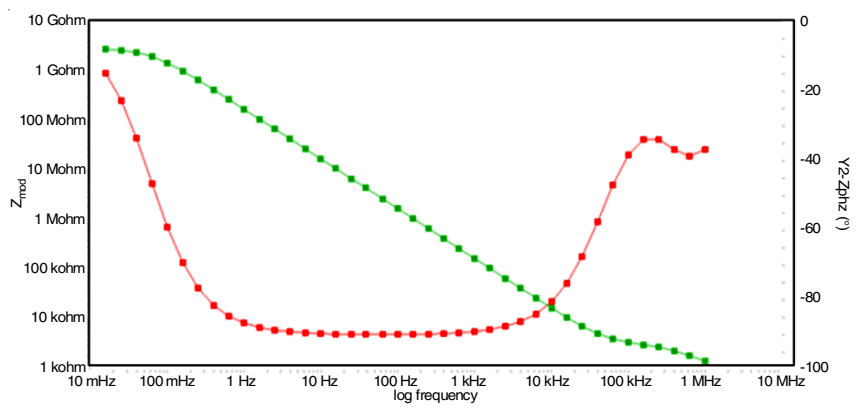

Fig. 7. Bode phase angle and IZI diagrams for planar BLM formed in $0.01 \mathrm{M} \mathrm{KCl}$ bath

At the highest range of frequencies, the overall impedance IZI of the bilayer membrane system is determined by the resistance of the bath solution $\left(\mathrm{R}_{\mathrm{s}}\right)$. Because at the highest range of frequencies the resistance of the bath solution is greater than $1 / \omega C_{p}$ and $1 / \omega C_{H}$. With further decrease in frequency $1 / \omega C_{H}$ is comparable with $\mathrm{R}_{\mathrm{H}}$ and the bode plot tends to become independent of applied frequencies. This corresponds to complete control of total impedance of bilayer lipid membrane by $\mathrm{R}_{\mathrm{H}}$ or membrane resistance $\mathrm{R}_{\mathrm{m}}$.

From Table-1, it is seen that the capacitance of polar region $\left(C_{P}\right)$ initially increases and then decreases when the lorazepam penetration caused a drastic change in the electrical properties of BLM. At higher concentration of lorazepam its fluidization effect will be large and increases the permeability of smaller ions across the BLM phase, before which the more number of charged species cross the solution - membrane interface and show higher capacitance value due to accumulation of ions. The variation of capacitance of BLM phase with cholesterol concentration in $\mathrm{KCl}$ bath solutions is shown in Fig. 8.

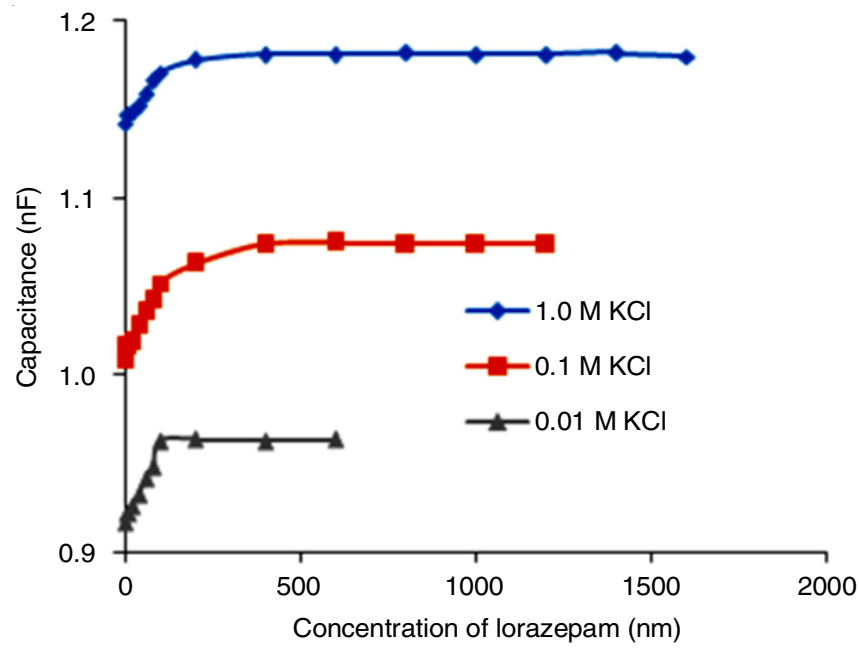

Fig. 8. Variation membrane capacitance with lorazepam concentration

It is seen (Fig. 8) that the capacitance of BLM phase increases gradually with cholesterol concentration and then showed a sudden jump. The initial increase in capacitance is due to penetration of lorazepam into the BLM phase, due to which the tightly bound phospholipid molecules are separated and the area of BLM increases.

The total membrane capacitance $\left(\mathrm{C}_{\mathrm{m}}\right)$, which has the contribution from both the bilayer hydrophobic domain $\left(\mathrm{C}_{\mathrm{H}}\right)$ and the two electrical double layers at the two membrane solution interfaces $\left(\mathrm{C}_{\mathrm{P}}\right)$, increases with drug dose, which can be explained based on discussions of Movileanu et al. [19] on the interaction of flavonoid quercetin with planar BLM as follows:

Since two capacitors $\mathrm{C}_{\mathrm{P}}$ and $\mathrm{C}_{\mathrm{H}}$ are in series

$$
\frac{1}{\mathrm{C}_{\mathrm{m}}}=\frac{1}{\mathrm{C}_{\mathrm{H}}}+\frac{2}{\mathrm{C}_{\mathrm{P}}}
$$

Accordingly

$$
\mathrm{C}_{\mathrm{m}}=\frac{\mathrm{C}_{\mathrm{H}} \mathrm{C}_{\mathrm{P}}}{\mathrm{C}_{\mathrm{P}}+2 \mathrm{C}_{\mathrm{H}}}
$$

The capacitance of the hydrophobic domain is associated with the thickness and the dielectric coefficient of the phospholipids hydrocarbon chain as

$$
\mathrm{C}_{\mathrm{H}}=\frac{\left(\varepsilon_{\mathrm{o}} \varepsilon_{\mathrm{H}}\right)}{\mathrm{d}_{\mathrm{H}}}
$$

where $\varepsilon_{\mathrm{H}}$ and $\mathrm{d}_{\mathrm{H}}$ are relative permittivity and thickness of the hydrocarbon core of the membrane, respectively. When the lorazepam molecules are inserted within the hydrophobic core of the lipid bilayer, the capacitance of the membrane system changes due to change in the capacitance of hydrophobic 

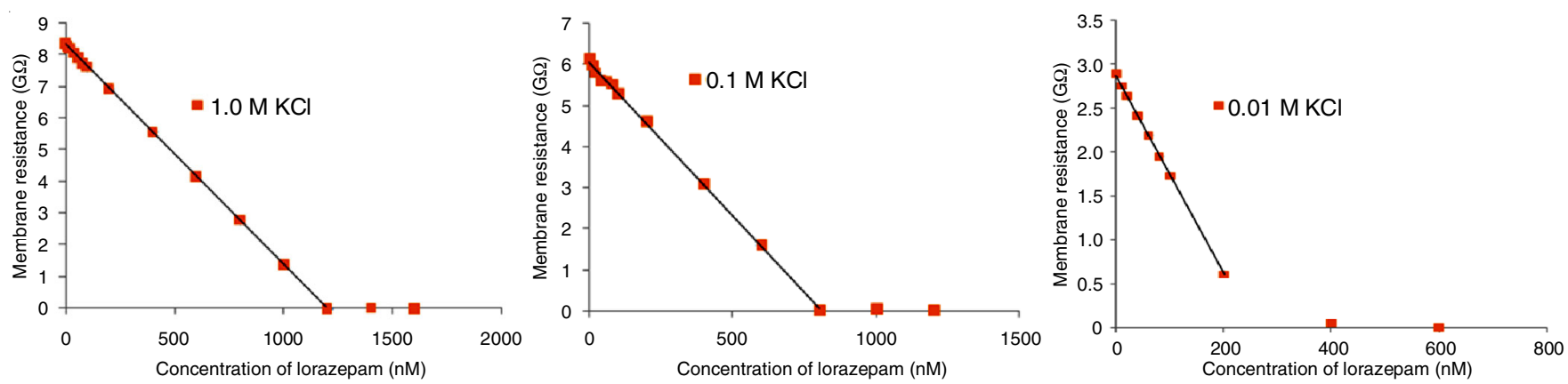

Fig. 9. Variation membrane resistance with the concentration of lorazepam in different $\mathrm{KCl}$ bath concentration

domain. Therefore, when the lorazepam molecules are inserted into the lipid bilayer, eqn. 5 changes as

$$
\mathrm{C}_{\mathrm{m}}^{\text {Lor }}=\frac{\mathrm{C}_{\mathrm{P}}\left(\mathrm{C}_{\mathrm{H}}+\mathrm{C}_{\mathrm{Lor}}\right)}{\mathrm{C}_{\mathrm{P}}+2\left(\mathrm{C}_{\mathrm{H}}+\mathrm{C}_{\text {Lor }}\right)}
$$

$\mathrm{C}_{\mathrm{m}}^{\mathrm{Lor}}$ can be expressed as a function which depends on the capacitance of the membrane in the absence of lorazepam, as follows

$$
\mathrm{C}_{\mathrm{m}}^{\mathrm{Lor}}=\left(\mathrm{C}_{\mathrm{m}}+\frac{\mathrm{C}_{\mathrm{P}} \mathrm{C}_{\mathrm{Lor}}}{\mathrm{C}_{\mathrm{P}}+\mathrm{C}_{\mathrm{H}}}\right) \times\left(\frac{\mathrm{C}_{\mathrm{P}}+2 \mathrm{C}_{\mathrm{H}}}{\mathrm{C}_{\mathrm{P}}+2 \mathrm{C}_{\mathrm{H}}+2 \mathrm{C}_{\mathrm{Lor}}}\right)
$$

where

$$
\mathrm{C}_{\text {Lor }}=\frac{\varepsilon_{\mathrm{o}} \varepsilon_{\text {Lor }}}{\mathrm{N}_{\text {Lor }} \mathrm{V}_{\text {Lor }}}
$$

$\mathrm{N}_{\mathrm{Lor}}=$ average number of lorazepam molecules per unit area of the bilayer, $\mathrm{V}_{\mathrm{Lor}}=$ the molecular volume of lorazepam, $\varepsilon_{\mathrm{Lor}}$ $=$ the dielectric coefficient of lorazepam.

The $\mathrm{C}_{\mathrm{Lor}}$ will be smaller than the other two components $\left(\mathrm{C}_{\mathrm{H}}\right)$ and $\left(\mathrm{C}_{\mathrm{P}}\right)$ even at very high concentrations of lorazepam, because the cross sectional area of phospholipid occupied domain is much higher than the cross-sectional area of the lorazepam occupied domain.

In this condition,

$$
\frac{\mathrm{C}_{\mathrm{P}}+2 \mathrm{C}_{\mathrm{H}}}{\mathrm{C}_{\mathrm{P}}+2 \mathrm{C}_{\mathrm{H}}+2 \mathrm{C}_{\text {Lor }}} \approx 1
$$

and

$$
\mathrm{C}_{\mathrm{m}}^{\mathrm{Lor}}=\left(\mathrm{C}_{\mathrm{m}}+\frac{\mathrm{C}_{\mathrm{P}} \mathrm{C}_{\mathrm{Lor}}}{\mathrm{C}_{\mathrm{P}}+\mathrm{C}_{\mathrm{H}}}\right)
$$

Hence $\mathrm{C}_{\mathrm{m}}$ increases with lorazepam concentration. A sudden jump in capacitance is due to replacement of large number of phospholipid molecules by lorazepam molecules.

Impedimetric sensor for lorazepam: The variation membrane resistance $\left(\mathrm{R}_{\mathrm{M}}\right)$ with the concentration of lorazepam in 1.0 M, 0.1 M and 0.01 M KCl bath solutions is shown in Fig. 9.

It is clear that the membrane resistance follows a linear relationship with lorazepam concentration up to 1200,800 and $200 \mathrm{nM}$ in $1.0,0.1$ and $0.01 \mathrm{M} \mathrm{KCl}$ bath solutions, respectively. The detection concentration range of lorazepam decreases with decrease in $\mathrm{KCl}$ concentration in bath solution. As explained above with increase in $\mathrm{KCl}$ concentration the binding of $\mathrm{Cl}^{-}$ ions on the surface of BLM increases. The binding of $\mathrm{Cl}^{-}$ions imparts a tightening effect on either side of BLM and makes it more stable and less permeable to ions. Due to same effect the thickness of BLM decreases with $\mathrm{KCl}$ concentration in the bath solution, which is attributed to the calculated capacitance values using eqn. 4.1. Hence a relatively more stable membrane formed in $1.0 \mathrm{M} \mathrm{KCl}$ bath solution withstand against fluidization effect of lorazepam and shows a linear relationship between membrane resistance and concentration of lorazepam.

\section{Conclusion}

Interaction of lorazepam with artificial planar bilayer phospholipid membrane was studied using electrochemical impedance spectroscopy. Lorazepam shows fluidization effect in the BLM and increases ionic conductance across BLM. The capacitance of BLM increases with lorazepam concentration. An impedimetric sensor was developed for the quantification of lorazepam in solution and detection level of lorazepam depends on bath concentration.

\section{CONFLICT OF INTEREST}

The authors declare that there is no conflict of interests regarding the publication of this article.

\section{REFERENCES}

1. A. Gliozzi and D.M. Robello, Colloids Surf., 35, 135 (1989); https://doi.org/10.1016/0166-6622(89)80292-6.

2. A.O. Leitmannova and H.T. Tien, Progr. Surf. Sci., 41, 337 (1992); https://doi.org/10.1016/0079-6816(92)90012-7.

3. M.K. Jain, The Bimolecular Lipid Membrane: A System, Van Nostrand Reinhold Compnay: New York (1972).

4. H.T. Tien and A.L. Ottova, J. Membr. Sci., 189, 83 (2001); https://doi.org/10.1016/S0376-7388(01)00394-5.

5. X. Lu, T. Liao, L. Ding, X. Liu, Y. Zhang, Y. Cheng and J. Du, Int. J. Electrochem. Sci. 3, 797 (2008).

6. J. Kotynska and Z.A. Figaszewski, Biochim. Biophys. Acta, 1720, 22 (2005); https://doi:10.1016/j.bbamem.2005.11.008.

7. R.I. Fryer, eds.: C. Hansch, P.G. Sammes, J.B. Taylor and C.A. Ramsden, Ligand Interactions at the Benzodiazepine Receptor, In: Comprehensive Medicinal Chemistry, Pergamon Press: New York, vol. 3, 539 (1990).

8. R.I. Fryer, ed.: E. Costa, The Benzodiazepines: From Molecular Biology to Clinical Practice, Raven Press: New York, vol. 7 (1983).

9. W.G. Tomas, ed.: E.F. Reynolds, Martindale-The Extra Pharmacopeias, The pharmaceutical Press: London, U.K., p. 605 (1993).

10. D.A. Garcia and M.A. Perillo, Biochim. Biophys. Acta, 1324, 76 (1997); https://doi.org/10.1016/S0005-2736(96)00210-6.

11. D.A. Garcia and M.A. Perillo, Biochim. Biophys. Acta, 1418, 221 (1999); https://doi.org/10.1016/S0005-2736(99)00040-1.

12. M.A. Perillo and A. Arce, J. Neurosci. Methods, 36, 203 (1991); https://doi.org/10.1016/0165-0270(91)90046-3.

13. E. Mallaiya, S. Rameshkumar, S.S. Subramanian, S. Ramalingam and T. Ramachandran, Electrochim. Acta, 13, 360 (2014); https://doi.org/10.1016/j.electacta.2014.06.038.

14. M. Kates, eds.: T.S. Work and E. Work, Techniques of Lipidology- Isolation, Analysis and Identification of Lipids, North-Holland Publishing Company: Amsterdam (1972). 
15. A. Hara and N.S. Radin, Anal. Biochem., 90, 420 (1978); https://doi.org/10.1016/0003-2697(78)90046-5.

16. L.A. Geddes, Electrodes and the Measurement of Bioelectric Events, Wiley Interscience, vol. 10 (1972). https://www.journals.uchicago.edu/doi/abs/10.1086/407587.

17. A.K. Corvington, Ion-Selective Electrode Methodology, CRC Press, Boca Raton: Florida, vol. 1 (1979).

18. Axon Guide-Axon Instruments, Inc. Product Information, January (2000).

19. L. Movileanu, I. Neagoe and M.L. Flonta, Int. J. Pharm., 205, 135 (2000); https://doi.org/10.1016/S0378-5173(00)00503-2.

20. M. Naumowicz, Z.A. Figaszewski, Bioelectrochemistry, 61, 21 (2003); https://doi: 10.1016/S1567-5394(03)00056-2.

21. H.G.L. Coster, eds.: A. Ottova-Leitmannova and H.T. Tien, Dielectric and Electrical Properties of Lipid Bilayers in Relation to their Structure, In: Planar Lipid Bilayers and their Applications, Amsterdam: Elsevier pp. $75-108$ (2003)

22. L.A. Geddes, Electrodes and the Measurement of Bioelectrical Events. Wiley-Interscience. pp. 99-102 (1972).

23. E.J. Corvington and E.J. Sitter, Skeletal Frame Structure with Sheet Material Cover, US Patent US 4,232,489 (1980).

24. V.F. de Lima, D. Scheller, F. Tegtmeier, W. Hanke and W.R. Schlue, Brain Res., 614, 45 (1993); https://doi.org/10.1016/0006-8993(93)91016-L.
25. B. Sakmann and E. Neher, Geometric Parameters of Pipettes and Membrane Patches, In: Single-Channel Recording, Springer: Boston, MA, pp. 37-51 (1983).

26. L. Becucci and R. Guidelli, Pharmaceuticals, 7, 136, (2014); https://doi.org/10.3390/ph7020136.

27. L. Becucci and R. Guidelli, Membranes, 6, 53, (2016) https://doi.org/10.3390/membranes6040053.

28. X. Han, Y. Tong, W. Huang and E. Wang, J. Electroanal. Chem., 523, 136 (2002); https://doi.org/10.1016/S0022-0728(02)00741-6.

29. A. Watts, K. Harlos and D. Marsh, Biochim. Biophys. Acta-Biomembr., 645, 91(1981); https://doi.org/10.1016/0005-2736(81)90515-0.

30. G. Favero, A. D’Annibale, L. Campanella, R. Santucci and T. Ferri, Anal. Chim. Acta, 460, 23 (2002); https://doi.org/10.1016/S0003-2670(02)00139-3

31. H. Kurishingal, P. Barain and C. Restall, Biochem. Soc. Trans., 20, 157S (1992); https://doi.org/10.1042/bst020157s 